\title{
KINERJA INVESTASI JASA PENGUJIAN TABLEWARE UNTUK PRODUK KREATIF KERAMIK PADA BTIKK-BPPT
}

\author{
I Nyoman Normal \\ Balai Teknologi Industri Kreatif Keramik (BTIKK)-Badan Pengkajian dan Penerapan Teknologi (BPPT) \\ Jl. By Pass Ngurah Rai Suwungkauh-Pemogan Denpasar, 80221, Indonesia
}

\begin{tabular}{|c|c|}
\hline \multirow{3}{*}{$\begin{array}{l}\text { Keywords: } \\
\text { Financial Analysis, } \\
\text { Investment, Table- } \\
\text { ware, Testing Service } \\
\text { JEL Classification: } \\
\text { D23, E22, G31 }\end{array}$} & Abstract \\
\hline & $\begin{array}{l}\text { The aims of this research was to analize the tableware testing service investment especially on ceramic } \\
\text { glaze for eating and drinking equipments at BTIKK-BPPT. The analysis techniques used were } \\
\text { payback period, net present value, profitability index, internal rate of return, and break even point. } \\
\text { The research results shew that the expansion investment of tableware testing service of ceramic on } \\
\text { glaze for eating and drinking equipments qualified by BSN according to SNI 7275:2008 was fea- } \\
\text { sible to be acted or applicated because they fulfilled the criteria of investment feasibility valuation, } \\
\text { namely: payback period analysis result was } 4,65 \text { years, in which its value was shorter than range } \\
\text { time of investment that was } 10 \text { years; net present value analysis result was IDR.206.043.764,69, in } \\
\text { which it was the positive value; profitability index analysis result was 1,41, in which its value was } \\
\text { over than 1,00; internal rate of return analysis result was 18,93\%, in which its value was over than } \\
10,00 \% \text {; and break even point analysis resulted } 2.567,56 \text { samples unit or IDR.256.911.104,11, in } \\
\text { which it was smaller than } 6.300,00 \text { samples unit or IDR.783.000.000,00. For all criteria, the analy- } \\
\text { sis of testing service investment (appearance, glazur hardness, temperature frightened tenacity, } \\
\text { water absorption, Cd E Pb solubility, glaze crack tenacity, and strike sturdy) was feasible to continue. }\end{array}$ \\
\hline & Abstrak \\
\hline $\begin{array}{l}\text { Kata kunci: } \\
\text { Analisis } \\
\text { Keuangan, } \\
\text { Investasi, Table- } \\
\text { ware, Jasa } \\
\text { Pengujian }\end{array}$ & $\begin{array}{l}\text { Penelitian ini bertujuan untuk menganalisis jasa pengujian produk kreatif keramik table- } \\
\text { ware, khususnya keramik berglasir untuk alat makan dan minum keramik di BTIKK-BPPT. } \\
\text { Teknik analisis yang digunakan adalah payback period, net present value, profitability index, } \\
\text { internal rate of return, dan break even point. Hasil penelitian menunjukkan bahwa perluasan } \\
\text { investasi jasa pengujian peralatan makan dari keramik berglasir untuk alat makan dan } \\
\text { minum berkualifikasi BSN sesuai dengan SNI 7275:2008 adalah layak untuk dilanjutkan } \\
\text { atau diaplikasikan karena telah memenuhi kriteria penilaian kelayakan investasi, yaitu: } \\
\text { hasil analisis payback period adalah } 4,65 \text { tahun, dimana nilainya lebih pendek dari rentang } \\
\text { waktu investasi } 10 \text { tahun; hasil analisis net present value adalah Rp.206.043.764,69, di mana } \\
\text { itu bernilai positif; hasil analisis indeks profitabilitas 1,41, dimana nilainya lebih dari dari } \\
\text { 1,00; hasil analisis internal rate of return adalah 18,93\%, dimana nilainya lebih dari dari } \\
\text { 10,00\%; dan break even point menghasilkan } 2.567,56 \text { unit sampel atau Rp.256.911.104,11, } \\
\text { dimana itu lebih kecil daripada } 6.300,00 \text { unit sampel atau Rp.783.000.000,00. Untuk semua } \\
\text { kriteria, analisis investasi jasa pengujian (kenampakan dan kegunaan, kekerasan, } \\
\text { ketahanan terhadap kejut suhu, penyerapan air, kelarutan Pb \& Cd, ketahanan terhadap } \\
\text { glasir, dan kuat pukul) adalah layak untuk dilanjutkan. }\end{array}$ \\
\hline
\end{tabular}




\section{Jurnal Keuangan dan Perbankan | KEUANGAN}

Vol. 21, No.1, Januari 2017: 47-59

Setiap perusahaan yang menjalankan kegiatan bisnis memiliki tujuan, baik tujuan jangka pendek maupun jangka panjang. Tujuan jangka pendek yang ingin dicapai oleh perusahaan adalah pencapaian laba atau keuntungan agar tersedianya dana yang kontinyu untuk bisa mengoperasikan perusahaan sehari-hari, sedangkan tujuan jangka panjang yang ingin dicapai adalah menjamin kelangsungan hidup perusahaan serta perkembangan di masa yang akan datang (Abdullah, 2015). Keputusan investasi adalah keputusan keuangan yang berkaitan dengan aktivitas investasi dalam berbagai bentuk (Wiagustini, 2014). Seorang investor menginvestasikan dana yang dimiliki dengan harapan akan mendapatkan return atau keuntungan dari perusahaan penerima dana (Rolita, 2014).

Investasi berarti pengeluaran dana saat ini dengan harapan memperoleh hasil atau keuntungan di masa yang akan datang (Wiagustini, 2014). Dilihat dari dimensi waktu, investasi dapat dikelompokkan menjadi dua, yaitu (1) Investasi jangka pendek (satu tahun atau kurang), yaitu investasi pada aktiva lancar (modal kerja), seperti: kas, piutang, inventori, surat-surat berharga; dan (2) Investasi jangka panjang (lebih dari satu tahun), yaitu: investasi pada asset riil, seperti: tanah, bangunan, peralatan, kantor, kendaraan, asset riil lainnya, dan investasi pada asset finansial seperti: investasi pada saham dan obligasi.

Suindrawan \& Sudiarta (2013) melakukan penelitian tentang analisis keuangan terhadap investasi pengadaan mesin pada UD Utama Denpasar, menghasilkan Payback Period (PP) 1 tahun 7 bulan 28 hari, Net Present Value (NPV) positif Rp446.314.013,00, Profitability Index (PI) 2,3, Internal Rate of Return (IRR) 61,60\%. Hasil penelitian tersebut memberikan pertimbangan kepada manajemen untuk melanjutkan investasi perluasan mesin karena secara finansial sangat layak atau menguntungkan perusahaan dalam jangka panjang.

Secara umum, tujuan suatu perusahaan adalah menciptakan kekayaan. Untuk mencapai tujuan tersebut, perusahaan harus memiliki produk yang dapat dijual kepada masyarakat (Rudianto, 2013). Keramik merupakan produk yang dibutuhkan oleh manusia sebagai alat rumah tangga, benda seni, alat pelengkap bangunan, dan sebagainya (Normal, 2013). Bali mempunyai potensi yang besar dalam pengembangan ekonomi kreatif karena mempunyai sumberdaya manusia yang kreatif dengan keragaman budaya dan ketersediaan bahan baku (Astiti, 2014). Dalam perencanaan jangka panjang, manajemen puncak menghadapi masalah penambahan mesin dan ekuipmen baru untuk memenuhi bertambahnya permintaan terhadap produk perusahaan, masalah penggantian aktiva tetap yang sudah tidak ekonomis pemakaiannya, dan masalah-masalah lain yang berhubungan dengan investasi atau penanaman modal (capital expenditure). Investasi umumnya membutuhkan dana yang relatif besar, dan keterikatan dana tersebut dalam jangka waktu yang relatif panjang, serta mengandung risiko, maka diperlukan pertimbangan yang masak sebelum investasi tersebut dilaksanakan (Mulyadi, 2013).

Balai Teknologi Industri Kreatif Keramik (BTIKK)-Badan Pengkajian dan Penerapan Teknologi (BPPT) sebagai salah satu lembaga pemerintah non kementerian yang tugas pokoknya di bidang penelitian dan pengembangan, perekayasaan, dan pelayanan jasa teknologi industri kreatif keramik, pada pada program jangka panjangnya ingin melakukan perluasan (ekspansi) usaha (kegiatan) di bidang jasa pengujian produk industri kreatif keramik khususnya tableware. Peraturan Pemerintah Republik Indonesia Nomor 6 tahun 2015 memuat tentang jenis dan tarif atas jenis penerimaan negara bukan pajak yang berlaku pada Badan Pengkajian dan Penerapan Teknologi, pada point IX (Jasa Teknologi dan Seni Keramik dan Porselin), disebutkan bahwa jasa teknologi yang ada atau berlaku ada 5 (lima), yaitu: Jasa pengolahan bahan baku siap pakai, jasa pelayanan bahan baku keramik siap bentuk, jasa teknologi pem- 
bakaran, jasa desain keramik, dan jasa pendidikan dan pelatihan keramik. Lima jenis jasa pelayanan teknologi yang telah ada saat ini rasanya belum cukup untuk menampung kebutuhan masyarakat pemerhati industri kreatif keramik yang semakin lama semakin berkembang baik pada tingkat lokal, nasional, maupun internasional. BTIKK-BPPT mulai tahun 2017 telah memrogramkan layanan jasa teknologi pengujian produk keramik khususnya tableware untuk membantu memberikan kontribusi bagi pemenuhan kebutuhan masyarakat dan kemajuan industri keramik di masa yang akan datang.

Jumlah investasi yang diperlukan untuk melakukan perluasan jasa pengujian produk kreatif keramik pada BTIKK-BPPT adalah Rp 500.000. 000,00, yang terdiri dari jasa pengujian: kenampakan (Knp) Rp3.150.000,00, kekerasan (Kkr) Rp 7.150.000,00, ketahanan kejut suhu (Kks) Rp 5.410. 000,00, penyerapan air (Pna) Rp 66.375.000,00, kelarutan $\mathrm{Cd} \& \mathrm{~Pb}(\mathrm{Kcp}) \mathrm{Rp} 105.600 .000,00$, ketahanan retak glasir (Krg) Rp 106.691.000,00, dan kuat pukul (Kpk) Rp63.050.000,00. Investasi untuk sarana pendukung lainnya yang diperkirakan sebesar Rp 142.584.000,00. Taksiran biaya yang dikeluarkan untuk melakukan kegiatan pengujian adalah Rp 84.070,55 per sampel uji untuk pengujian kenampakkan dengan tarif Rp 100.000,00 per sampel, sebesar Rp 66.534,05 per sampel uji untuk pengujian kekerasan dengan tarif $\operatorname{Rp} 75.000,00$ per sampel, sebesar Rp 124.964,40 per sampel uji untuk pengujian kejut suhu dengan tarif Rp150.000,00 per sampel, sebesar Rp59.461,64 per sampel uji untuk pengujian penyerapan air dengan tarif Rp75.000,00 per sampel, sebesar Rp 132.158,46 per sampel uji untuk pengujian kelarutan $\mathrm{Cd} \& \mathrm{~Pb}$ dengan tarif Rp 170.000,00 per sampel, sebesar Rp 150.552,13 per sampel uji untuk pengujian ketahanan retak glasir dengan tarif Rp 200.000,00 per sampel, dan sebesar Rp77.046,05 per sampel uji dengan tarif Rp $100.000,00$ per sampel.

Tujuan penelitian ini adalah: (1) Untuk mengetahui tingkat kelayakan perluasan investasi jasa pengujian produk kreatif keramik pada BTIKKBPPT ditinjau dari sisi kriteria penilaian investasi manajemen keuangan, yaitu payback period (PP), net present value (NPV), profitability index (PI), internal rate of return (IRR), dan break even point (BEP); (2) Untuk memberikan dasar pengambilan keputusan melanjutkan atau meghentikan investasi bagi BTIKK-BPPT; (3) Untuk alat promosi produk kreatif berupa tableware yang telah melalui proses pengujian, khususnya untuk wilayah Indonesia Timur; dan (4) Untuk menambah referensi bagi kalangan akademisi, praktisi, pengusaha, dan fungsional lain dalam melakukan penelitian investasi jasa pengujian sehingga memperoleh hasil penelitian yang lebih baik.

Investasi adalah pengkaitan sumber-sumber dalam jangka panjang untuk menghasilkan laba di masa yang akan datang (Mulyadi, 2013). Investasi banyak mengandung risiko dan ketidakpastian. Haming \& Murdifin (2010) menyatakan bahwa investasi adalah pengeluaran untuk mengadakan barang modal pada saat sekarang dengan tujuan untuk menghasilkan keluaran barang atau jasa agar dapat diperoleh manfaat yang lebih besar di masa yang akan datang, selama dua tahun atau lebih. Pusat investasi adalah pusat pertanggungjawaban yang manajernya bertanggung-jawab terhadap pendapatan, biaya, dan investasi yang terjadi pada pusat pertanggungjawaban tersebut (Suindrawan \& Sanjaya, 2012). Salah satu penggolongan usul-usul investasi didasarkan menurut kategori di bawah ini (Riyanto, 2011): (1) investasi penggantian; (2) investasi penambahan kapasitas; (3) investasi penambahan jenis produk baru; dan (4) investasi lain-lain.

Ada beberapa metode dapat digunakan untuk mengevaluasi keputusan investasi (Wiagustini, 2014), yaitu: (1) metode payback period (PP), yaitu metode yang mencoba mengukur seberapa cepat suatu investasi bisa kembali; (2) metode net present value (NPV), yaitu: metode yang menghitung selisih present value (nilai sekarang) investasi dengan 


\section{Jurnal Keuangan dan Perbankan | KEUANGAN}

Vol. 21, No.1, Januari 2017: 47- 59

present value kas masuk bersih (proceeds); (3) metode profitability index (PI), yaitu metode yang menunjukkan perbandingan antara PV proceeds dengan PV investasi; dan (4) metode internal rate of return (IRR), yaitu metode yang menunjukkan tingkat bunga yang menyamakan PV proceeds dan PV investasi. Sebagai kelengkapan dari analisis pengujian investasi dan perencanaan (pengendalian) laba, dapat juga digunakan analisis break even point (BEP) yang mengkhususkan perhatian lebih besar terhadap contribution margin (CM). Analisis CM sangat diperlukan, karena dengan cepat pula dapat membuat suatu keputusan dan sebagai titik awal dari keputusan-keputusan berikutnya. Break even point kombinasi produk (product mix) harus dengan asumsi proporsi atau kecil kombinasi konstan (misalnya produk A3 unit, produk B4 unit, dan produk C5 unit).

Baridwan (2000) menyatakan aktiva tetap adalah aktiva-aktiva yang dapat digunakan lebih dari satu periode, seperti: tanah, gedung- gedung, mesin dan alat-alat, perabot, kendaraan, dan lainlain. Pengertian aktiva tetap menurut IAI PSAK No.16 (2004) adalah aktiva tetap berwujud yang diperoleh dalam bentuk siap pakai atau dengan dibangun terlebih dahulu yang digunakan dalam operasi perusahaan dan mempunyai masa manfaat lebih dari satu tahun. Menurut Rudianto (2008), aktiva tetap dikelompokkan dalam beberapa kriteria: (a) berwujud; (b) umurnya lebih dari satu tahun; (c) digunakan dalam operasi perusahaan; (d) tidak diperjualbelikan; (e) material; dan (f) dimiliki perusahaan.

Menurut Badan Standarisasi Nasional/BSN (2008), Standar Nasional Indonesia (SNI) 7275:2008 keramik berglasir tableware alat makan dan minum, merupakan standar baru yang menggantikan empat SNI sebelumnya, yaitu: SNI 12-2124-1996 (alat minum teh atau kopi keramik rumah tangga jenis semi porselin dan porselin, SNI 15-2579-1992 (gerabah halus berglasir timbal untuk alat makan dan minum, SNI 12-2099-1996 (cara uji pelarutan timbal dan cadmium pada alat makan minum, dan SNI 12-2580-1996 (alat makan minum keramik hotel jenis vitrified china atau porselin keramik). Standar ini disusun dengan tujuan: melindungi konsumen, melindungi produsen, dan memberikan rasa aman bagi pengguna.

Standar ini menetapkan stoneware yang digunakan untuk alat makan dan minum dari keramik terdiri dari majolica, fine earthenware, semi vitreous china/semi porselin, stoneware, bone china, dan porselin yang berglasir. Tableware yang digunakan untuk alat makan dan minum dari keramik berglasir dapat berbentuk datar dan/atau berongga. Klasifikasi tableware adalah sebagai berikut: (1) barang datar (tinggi maksimal $35 \mathrm{~mm}$ ), dengan produk berupa: pisin, piring makan, piring sambal, dan sebagainya; dan (2) barang berongga, a) kecil, dengan produk berupa: cangkir, mangkok (bowl), teko, mug, dan sebagainya, dengan kapasitas isi kurang $1.100 \mathrm{ml}$, dan b) besar, dengan produk berupa tempat nasi, tempat sayur, dan sebagainya, dengan kapasitas lebih dari atau sama dengan $1.100 \mathrm{ml}$. Persyaratan yang ditetapkan oleh BSN dalam SNI 7275:2008, bahwa barang keramik berupa tableware dimaksud harus memenuhi syarat mutu, yang terdiri dari: a) sifat tampak, b) kekerasan, c) ketahanan retak glasir, d) ketahanan terhadap kejut suhu, e) penyerapan air, f) ketahanan pukul, dan g) batas kelarutan maksimum Plumbum $(\mathrm{Pb})$ dan Cadmium (Cd). Sudana (2014) berpendapat bahwa apabila produk-produk gerabah baru hasil revitalisasi akan diproduksi dan dipasarkan secara luas, maka untuk mengawasi kualitas hasil-hasil produksi dari para perajin tradisional, pemerintah melalui instansi terkait perlu membentuk gugus kendali mutu (GKM) guna mengontrol dan membuat standar tentang kualitas hasil produksi, sehingga konsumen senantiasa mendapat produk yang memenuhi standar kualitas. Standar tarif pengujian keramik berglasir alat makan dan minum keramik menurut Balai Besar Industri Keramik (BBIK) Bandung adalah: (1) kenampakan 
dan kegunaan Rp100.000,00/contoh; (2) kekerasan Rp75.000,00/contoh; (3) ketahanan terhadap kejut suhu Rp150.000,00/contoh; (4) penyerapan air Rp75.000,00/contoh; (5) kelarutan $\mathrm{Pb}$ dan $\mathrm{Cd}$ Rp170.000,00/contoh; (6) ketahanan terhadap glasir Rp200.000,00/contoh; dan (7) kuat pukul Rp100.000,00/contoh.

Abdullah (2015) meneliti analisis kelayakan investasi ativa tetap pembelian mesin printing pada PT Radja Digital Printing Samarinda. Permasalahannya apakah investasi pembelian (penggantian) mesin printing pada PT Radja Digital Printing Samarinda layak dari sisi keuangan. Umur proyek diperkirakan lima tahun. Hasil penelitiannya menunjukkan besarnya NPV Rp 1.063. $315.999,00>1$, besar IRR 17,00\%>16,00\%, PP 1 tahun 1 bulan $<5$ tahun, dan PI 4,00 $>1$. Disimpulkan bahwa investasi aktiva tetap pembelian mesin printing pada PT Radja Digital Printing Samarinda adalah layak dan wajar untuk dilaksanakan atau diteruskan.

Penelitian investasi oleh Suindrawan \& Sudiarta (2013) tentang analisis reevaluasi investasi aktiva tetap ditinjau dari aspek finansial pada UD Utama Denpasar dilakukan untuk mengetahui apakah investasi aktiva tetap yang sudah dilakukan pada UD Utama layak atau tidak, ditinjau dari aspek finansialnya. Umur proyek diperkirakan lima tahun, terhitung mulai tahun 2007 s.d 2011. Hasil penelitian menunjukkan bahwa PP 1 tahun 7 bulan 28 hari $<8$ tahun, NPV Rp446.314.013,00> 0, PI 2,30>1, dan IRR $61,60 \%>18,00 \%$. Dapat disimpulkan bahwa investasi pembelian mesin yang dilakukan oleh UD Utama Denpasar layak untuk dilanjutkan atau menguntungkan untuk dilanjutkan.

Rolita (2014) meneliti tentang hubungan struktur modal dan keputusan investasi pada perusahaan manufaktur. Permasalahannya adalah seandainya perusahaan mengganti sebagian modal sendiri dengan utang (atau sebaliknya), apakah aset tetap akan berubah apabila perusahaan tidak merubah keputusan keuangan lainnya? Dengan menggunakan analisis regresi linier berganda, maka hasil perhitungan diperoleh bahwa LDAR, LDER, dan EAR tidak berpengaruh signifikan terhadap perubahan aset tetap, sedangkan DAR dan DER berpengaruh signifikan terhadap perubahan aset tetap. Disimpulkan bahwa utang akan memengaruhi keputusan investasi khususnya investasi real asset yang berupa aset tetap.

\section{METODE}

Bahan yang digunakan dalam penelitian ini adalah investasi aktiva tetap dalam rangka perluasan (ekspansi) usaha jasa pengujian produk kreatif keramik tableware, khususnya keramik berglasir untuk alat makan dan minum keramik sebagai pemenuhan kewajiban industri keramik memenuhi mutu keramik sesuai dengan SNI 7275:2008. Jenis data yang digunakan: (1) data kualitatif, yaitu aktiva tetap yang digunakan dalam proses pengujian, proses pengujian, dan jenis bahan dan tenaga yang diperlukan dalam proses pengujian; dan (2) data kuantitatif, yaitu harga perolehan aktiva tetap, kuantitas dan biaya bahan pengujian, biaya listrik, biaya telepon, biaya air, biaya tenaga kerja selama proses pengujian, komposisi marjin kontribusi jasa pengujian, jam mesin, jam tenaga kerja langsung, dan Upah Minimum Kota Denpasar.

Sumber data berasal dari: (1) data primer, yaitu aktiva tetap, biaya telepon, biaya air, jam mesin, jam tenaga kerja langsung, komposisi jasa pengujian, penggunaan bahan baku, biaya pemeliharaan, dan jumlah tenaga kerja langsung; dan (2) data sekunder, yaitu: upah minimum Kota Denpasar dari Depnakertrans, jenis tarif dari Balai Besar Industri Keramik Bandung, dan standar peresapan air yang memenuhi syarat sebagai stoneware dari American Standard Testing Material (ASTM), dan standar mutu pengujian tableware dari Badan Standarisasi Nasional (BSN).

Metode yang digunakan dalam analisis penelitian ini adalah: (1) mengidentifikasi proses 
pengujian mutu keramik tableware dan mengumpulkan data hasil pengujian; (2) mengestimasi jumlah penjualan (pendapatan) dan biaya atas ketujuh jenis jasa pengujian dan mengumpulkan hasinya yang akan digunakan dasar perhitungan laba setelah pajak; (3) menghitung beban penyusutan dalam proses perolehan pendapatan dari ketujuh jenis pengujian; dan (4) menghitung aliran kas operasional (operasional cash flow) selama umur proyek (investasi) dengan cara menjumlahkan laba bersih setelah pajak dan biaya penyusutan; (5) memisahkan dan menghitung besarnya biaya variabel dan tetap dari aktivitas pengujian produk kreatif keramik; (6) mengestimasi komposisi marjin kontribusi dari ketujuh jenis pengujian; (7) menetapkan tingkat bunga normal untuk perhitungan nilai sekarang (present value); (8) menghitung uji kelayakan investasi, yaitu: PP, NPV, PI, dan IRR; (9) menghitung tingkat BEP proyek (investasi); (10) membandingkan hasil uji investasi sesungguhnya dengan kriteria uji yang diharapkan; dan (11) membuat simpulan apakah investasi (proyek) layak untuk diteruskan atau dilanjutkan. Teknik analisis data yang digunakan dijelaskan sebagai berikut.

Payback period (PP) digunakan untuk menentukan dalam berapa tahun modal yang ditanamkan akan kembali. Kriteria seleksi adalah jika payback period lebih kecil dibanding dengan target kembalinya investasi maka proyek investasi layak, sebaliknya jika payback period lebih besar dibanding dengan target kembalinya investasi maka proyek tidak layak. PP dapat dirumuskan sabagai berikut (Sutrisno, 2009):

$\mathrm{PP}=($ Investasi: Aliran Kas $) \times 1$ tahun.

Net present value (NPV), untuk menghitung selisih present value (nilai sekarang) investasi dengan present value kas masuk bersih (proceeds). Kriteria penilaian investasinya adalah terima suatu usulan investasi yang diharapkan memberikan NPV positif, dan tolak kalau memberikan NPV negatif. NPV dapat dirumuskan sebagai berikut (Wiagustini, 2014):
$\mathrm{NPV}=\left\{\mathrm{A} 1 /(1+\mathrm{r})+\mathrm{A} 2 /(1+\mathrm{r})^{2}+\ldots \mathrm{An} /(1+\mathrm{r})^{\mathrm{n}}\right\}-\mathrm{I}_{\mathrm{o}}$

Dimana:

$$
\begin{array}{ll}
\mathrm{A} & =\text { kas masuk bersih (proceeds) } \\
\mathrm{r} & =\text { suku bunga } \\
\mathrm{t} & =\text { waktu (tahun) } 1 \text { sampai } \mathrm{n} \\
\mathrm{n} & =\text { umur investasi } \\
\mathrm{I}_{\mathrm{o}} & =\text { investasi awal. }
\end{array}
$$

Profitability index (PI) digunakan untuk menunjukkan perbandingan antara PV proceeds dengan PV investasi. Kriteria penilaian yang digunakan adalah: terima investasi yang diharapkan memberikan PI $>1$. Profitability Index (PI) dapat dirumuskan sebagai berikut (Wiagustini, 2014):

$$
\text { PI }=(\text { PV Proceeds } / \text { PV Investasi })
$$

Internal rate of return (IRR) menunjukkan tingkat bunga yang menyamakan PV proceeds dan PV investasi. Kriteria penilaian investasinya adalah terima investasi yang diharapkan memberikan IRR $>$ tingkat bunga yang dipandang layak. Perhitungan IRR dapat dirumuskan sebagai berikut (Wiagustini, 2014):

$\mathrm{IRR}=\mathrm{r}_{1}+\left(\left(\mathrm{NPV}_{1} / \mathrm{PV}_{1}-\mathrm{PV}_{2}\right) \times\left(\mathrm{r}_{2}-\mathrm{r}_{1}\right)\right)$

dimana:

$\mathrm{r}_{1} \quad=$ suku bunga yang menghasilkan $P V$ positif, $\mathrm{r}_{2}=$ suku bunga yang menghasilkan $P V$ negatif, $P V_{1}=P V$ pada suku bunga $r_{1}, P V_{2}=P V$ pada suku bunga $r_{2}$, dan $N P V_{1}=$ Net Present Value pada bunga $r_{1}$

Break even point (BEP) menunjukkan suatu titik atau keadaan dimana perusahaan atau organisasi tidak memperoleh keuntungan dan tidak menderita kerugian atau dalam keadaan impas (pulang pokok). Kriteria kelayakannya adalah terima investasi yang memberikan tingkat penjualan produk atau jasa yang diharapkan yang di atas BEP, untuk beberapa jenis produk atau jasa dapat dirumuskan sebagai berikut: 
$\mathrm{BEP}=\left((\right.$ Biaya Tetap $) /\left(\mathrm{MK}_{\mathrm{A}} \mathrm{x}\right.$ Prop. $\left._{\mathrm{A}}\right)+\left(\mathrm{MK}_{\mathrm{B}} \mathrm{x}\right.$ Prop. $\left._{\mathrm{B}}\right)+\ldots\left(\mathrm{MK}_{\mathrm{N}} \times\right.$ Prop. $\left.\left._{\mathrm{N}}\right)\right)$

Dimana:

$\mathrm{MK}_{\mathrm{A}} \quad=$ Marjin Kontribusi Produk A

$\mathrm{MK}_{\mathrm{B}} \quad=$ Marjin Kontribusi Produk B

$\mathrm{MK}_{\mathrm{N}} \quad=$ Marjin Kontribusi Produk N

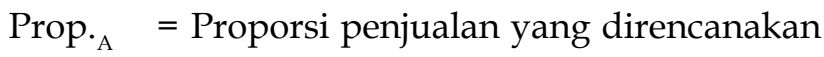
atas produk $\mathrm{A}$

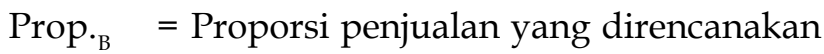
atas produk B

Prop $_{\mathrm{N}} \quad=$ Proporsi penjualan yang direncanakan atas produk $\mathrm{N}$

\section{HASIL}

\section{Analisis Payback Period (PP)}

Hasil perhitungan PP investasi jasa pengujian (kenampakan \& kegunaan, kekerasan, ketahanan terhadap kejut suhu, penyerapan air, kelarutan $\mathrm{Pb}$ \& Cd, ketahanan terhadap glasir, dan kuat pukul) mutu keramik berglasir untuk alat makan dan minum keramik pada BTIKK-BPPT ditunjukkan pada Tabel 1.

Tabel 1 menunjukkan bahwa rencana investasi sebesar Rp500.000.000,00 untuk pembelian aktiva tetap dan perlengkapan lainnya atas jasa pengujian akan menghasilkan aliran kas masuk (proceeds) tahunan sebesar Rp114.906.626,20. Jumlah tersebut didapat dari penjumlahan laba bersih setelah pajak ditambah biaya penyusutan. Investasi tersebut akan digunakan untuk kegiatan alat pengujian (kenampakan \& kegunaan, kekerasan, ketahanan terhadap kejut suhu, penyerapan air, kelarutan $\mathrm{Pb} \& \mathrm{Cd}$, ketahanan terhadap glasir, dan kuat pukul) mutu keramik mulai tahun 2017. Umur investasi diperkirakan selama 10 tahun. Dengan menggunakan rumus payback period, yaitu mengurangkan jumlah investasi dengan proceeds tahunan setiap tahun sampai mencapai jumlah investasi sebesar Rp500.000.000,00, maka didapat payback period 4 tahun 7,78 bulan.

\section{Analisis Net Present Value (NPV)}

Hasil perhitungan NPV investasi jasa pengujian (kenampakan \& kegunaan, kekerasan, ketahanan terhadap kejut suhu, penyerapan air, kelarutan $\mathrm{Pb} \& \mathrm{Cd}$, ketahanan terhadap glasir, dan kuat pukul) mutu keramik berglasir untuk alat makan dan minum keramik pada BTIKK-BPPT ditunjukkan pada Tabel 2.

Tabel 2 menunjukkan bahwa rencana investasi yang dilakukan sebesar Rp500.000.000,00 untuk pembelian aktiva tetap dan perlengkapan lainnya atas jasa pengujian akan menghasilkan aliran kas masuk (proceeds) tahunan sebesar Rp114.906. 626,20 . Tingkat bunga yang layak digunakan da-

Tabel 1. Payback Period Investasi Jasa Pengujian Mutu Keramik Berglasir untuk Alat Makan dan Minum Keramik

\begin{tabular}{|c|c|c|c|c|c|c|}
\hline \multirow{2}{*}{$\begin{array}{c}\text { Total } \\
\text { Investasi } \\
\text { Rp }\end{array}$} & \multirow{2}{*}{$\begin{array}{c}\text { Proceeds } \\
\text { Tahunan } \\
\text { Rp }\end{array}$} & \multirow{2}{*}{$\begin{array}{c}\text { Estimasi Umur } \\
\text { Proyek } \\
\text { Tahun }\end{array}$} & \multicolumn{2}{|c|}{$\begin{array}{c}\text { Payback } \\
\text { Period (PP) }\end{array}$} & \multirow{2}{*}{$\begin{array}{c}\text { Kriteria } \\
\text { Keputusan } \\
-\end{array}$} & \multirow{2}{*}{$\begin{array}{c}\text { Keputusan } \\
\text { Investasi } \\
-\end{array}$} \\
\hline & & & Tahun & Bulan & & \\
\hline $500.000 .000,00$ & $114.906 .626,20$ & 10 & 4 & 7,78 & PP < Umur Proyek & Layak \\
\hline
\end{tabular}

Tabel 2. Net Present Value Investasi Jasa Pengujian Mutu Keramik Berglasir untuk Alat Makan dan Minum Keramik

\begin{tabular}{ccccccc}
\hline $\begin{array}{c}\text { Total } \\
\text { Investasi } \\
\mathbf{R p}\end{array}$ & $\begin{array}{c}\text { Proceeds } \\
\text { Tahunan } \\
\mathbf{R p}\end{array}$ & $\begin{array}{c}\text { Discount } \\
\text { Factor } \\
\mathbf{\%}\end{array}$ & $\begin{array}{c}\mathbf{P V} \\
\text { Proceeds } \\
\mathbf{R p}\end{array}$ & $\mathbf{N P V}$ & $\begin{array}{c}\text { Kriteria } \\
\text { Keputusan } \\
-\end{array}$ & $\begin{array}{c}\text { Keputusan } \\
\text { Investasi } \\
-\end{array}$ \\
\hline $500.000 .000,00$ & $114.906 .626,20$ & 10,00 & $706.043 .764,69$ & $206.043 .764,69$ & NPV Positif & Layak \\
\hline
\end{tabular}


lam penelitian saat ini adalah $10,00 \%$. Discount factor atas aliran kas masuk (proceeds) dengan tingkat bunga $10,00 \%$ berkisar dari 0,9091 s.d 0,3885 selama sepuluh tahun. Dengan mengalikan aliran kas masuk (proceeds) tahunan dengan discount factor tahun yang bersangkutan akan diperoleh PV proceeds, yang jumlah totalnya selama sepuluh tahun adalah Rp706.043.764,69. Dengan mengurangkan PV investasi dari PV proceeds, maka akan didapat NPV yang besarnya Rp206.043.764,69.

\section{Analisis Profitability Index (PI)}

Hasil perhitungan PI investasi jasa pengujian (kenampakan \& kegunaan, kekerasan, ketahanan terhadap kejut suhu, penyerapan air, kelarutan $\mathrm{Pb}$ \& Cd, ketahanan terhadap glasir, dan kuat pukul) mutu keramik berglasir untuk alat makan dan minum keramik pada BTIKK-BPPT ditunjukkan pada Tabel 3.

Tabel 3 menunjukkan bahwa rencana investasi sebesar Rp500.000.000,00 untuk pembelian aktiva tetap dan perlengkapan lainnya atas jasa pengujian keramik akan menghasilkan aliran kas masuk (proceeds) tahunan sebesar Rp114. 906.626,20. Tingkat bunga yang layak digunakan dalam penelitian saat ini adalah $10,00 \%$. Discount factor atas aliran kas masuk (proceeds) dengan tingkat bunga $10,00 \%$ berkisar dari 0,9091 s.d 0,3885 selama sepuluh tahun. Dengan mengalikan aliran kas masuk (proceeds) tahunan dengan discount fac- tor tahun yang bersangkutan akan diperoleh PV proceeds, yang jumlah totalnya selama sepuluh tahun adalah Rp706.043.764,69. Dengan membagi PV proceeds dengan PV investasi, maka akan didapat PI sebesar 1,41 .

\section{Analisis Internal Rate of Return (IRR)}

Hasil perhitungan IRR investasi jasa pengujian (kenampakan \& kegunaan, kekerasan, ketahanan terhadap kejut suhu, penyerapan air, kelarutan $\mathrm{Pb} \& \mathrm{Cd}$, ketahanan terhadap glasir, dan kuat pukul) mutu keramik berglasir untuk alat makan dan minum keramik pada BTIKK-BPPT ditunjukkan pada Tabel 4 .

Tabel 4 menunjukkan bahwa rencana investasi Rp500.000.000,00 untuk pembelian aktiva tetap dan perlengkapan lainnya atas jasa pengujian keramik akan menghasilkan aliran kas masuk (proceeds) tahunan sebesar Rp114.906.626,20. Tingkat bunga1 (yang menghasilkan NPV positif) adalah 10,00\%), sedangkan tingkat bunga-2 (yang menghasilkan NPV negatif) adalah 19,00\%. PV proceeds-1 (yang menghasilkan NPV positif) dengan tingkat bunga 10,00\% adalah Rp706.043.754,69, sedangkan PV proceeds-2 (yang menghasilkan NPV negatif) dengan tingkat bunga 19,00\% adalah Rp498. 568.360,42. NPV-1 yang dihasilkan adalah Rp206. 043.764,69, sedangkan NPV-2 adalah (Rp1.431. 639,58). Dengan memasukkan angka-angka komponen $I R R$, yaitu tingkat bunga-1, tingkat bunga-

Tabel 3. Profitability Index Investasi Jasa Pengujian Mutu Keramik Berglasir untuk Alat Makan dan Minum Keramik

\begin{tabular}{|c|c|c|c|c|c|c|}
\hline $\begin{array}{c}\text { Total } \\
\text { Investasi }\end{array}$ & $\begin{array}{l}\text { Proceeds } \\
\text { Tahunan }\end{array}$ & $\begin{array}{l}\text { Discount } \\
\text { Factor }\end{array}$ & $\begin{array}{c}\text { PV } \\
\text { Proceeds }\end{array}$ & $P I$ & $\begin{array}{c}\text { Kriteria } \\
\text { Keputusan }\end{array}$ & $\begin{array}{c}\text { Keputusan } \\
\text { Investasi }\end{array}$ \\
\hline $\mathbf{R p}$ & $\mathbf{R p}$ & $\%$ & $\mathbf{R p}$ & $\mathbf{R p}$ & - & - \\
\hline $500.000 .000,00$ & $114.906 .626,20$ & 10,00 & $706.043 .764,69$ & 1,41 & $\mathrm{PI}>1$ & Layak \\
\hline
\end{tabular}

Tabel 4. Internal Rate of Return Investasi Jasa Pengujian Mutu Keramik Berglasir Untuk Alat Makan dan Minum Keramik

\begin{tabular}{|c|c|c|c|c|c|c|}
\hline $\begin{array}{c}\text { Tingat } \\
\text { Bunga-1 } \\
0 \%\end{array}$ & $\begin{array}{c}\text { Tingat } \\
\text { Bunga-2 } \\
\% \%\end{array}$ & $\begin{array}{c}P V \\
\text { Proceeds-1 } \\
\text { Rp }\end{array}$ & $\begin{array}{c}P V \\
\text { Proceeds-2 } \\
\text { Rp }\end{array}$ & $I R R$ & $\begin{array}{c}\text { Kriteria } \\
\text { Keputusan } \\
-\end{array}$ & $\begin{array}{c}\text { Keputusan } \\
\text { Investasi } \\
-\end{array}$ \\
\hline 10,00 & 19,00 & $706.043 .764,69$ & $498.568 .360,42$ & 18,93 & IRR > Tk. Bunga yang layak & Layak \\
\hline
\end{tabular}


2, NPV-1, PV proceeds-1, dan PV proseeds-2 kedalam rumus IRR, maka diperoleh nilai IRR sebesar $18,93 \%$.

\section{Analisis Break Even Point (BEP)}

Hasil perhitungan BEP investasi jasa pengujian (kenampakan \& kegunaan, kekerasan, ketahanan terhadap kejut suhu, penyerapan air, kelarutan $\mathrm{Pb} \& \mathrm{Cd}$, ketahanan terhadap glasir, dan kuat pukul) mutu keramik berglasir untuk alat makan dan minum keramik pada BTIKK-BPPT ditunjukkan pada Tabel 5.

Tabel 5 menunjukkan bahwa investasi sebesar Rp500.000.000,00 untuk pembelian aktiva tetap dan perlengkapan lainnya atas jasa pengujian keramik akan dikeluarkan biaya tetap sebesar Rp53. 319.900,00. Marjin kontribusi masing-masing jenis pengujian ditentukan dengan mengurangkan biaya variabel dari harga jual. Proporsi penjualan masingmasing jenis jasa pengujian dihitung dengan membandingkan kemungkinan penjualan setiap jenis pengujian dengan total penjualan yang terjadi. Perkalian marjin kontribusi dengan proporsi masing-masing jenis pengujian akan diperoleh marjin kontribusi dlam proporsi, yang jumlah totalnya sebesar Rp21.696,29/unit. Berdasarkan rumus BEP yang ada, maka diperoleh nilai BEP dalam unit sebanyak 2.457,56 unit dan dalam rupiah sebesar Rp256.911.104,11.

\section{PEMBAHASAN}

Badan Standarisasi Nasional (BSN) menyaratkan bahwa semua produk keramik tableware khu- susnya keramik berglasir untuk alat makan dan minum keramik harus memenuhi mutu sesuai Standar Nasional Indonesia (SNI) 7275:2008. Untuk melakukan pengujian mutu tersebut (kenampakan \& kegunaan, kekerasan, ketahanan terhadap kejut suhu, penyerapan air, kelarutan $\mathrm{Pb} \& \mathrm{Cd}$, ketahanan terhadap glasir, dan kuat pukul), maka BTIKK-BPPT telah menyusun rencana investasi sehingga dapat melakukan tugas dan fungsi pokoknya sebagai lembaga pengujian khususnya untuk Indonesia Bagian Timur. Untuk menetapkan keputusan tersebut, BTIKK-BPPT telah melakukan analisis keuangan terhadap investasi aktiva tetap yang kemungkinan akan digunakan dalam proses pengujian tersebut. Analisis mencakup lima kriteria penting yang dianggap cukup mewakili analisis keuangan investasi dalam manajemen keuangan, yang terdiri: payback period, net present value, profitability index, internal rate of return, dan break even point.

Analisis payback period memberikan hasil sebesar 4,65 tahun, artinya investasi pengujian akan kembali modalnya dalam waktu 4,65 tahun dari 10 tahun waktu proyek atau investasi yang direncanakan. Dalam analisis payback period faktor yang menentukan penerimaan atau penolakan suatu usulan investasi adalah jangka waktu yang diperlukan untuk menutup kembali investasi. Oleh sebab itu, dengan metode ini setiap usulan investasi dinilai berdasarkan apakah dalam jangka waktu sepuluh tahun yang diinginkan oleh manajemen, jumlah kas masuk bersih rata-rata per tahun atau biaya diferensial tunai yang berupa penghematan tunai (cash saving) per tahun yang diperoleh dari investasi dapat menutup investasi yang direncanakan. Metode payback period bukan merupakan pengukur

Tabel 5: Break Even Point Investasi Jasa Pengujian Mutu Keramik Berglasir Untuk Alat Makan dan Minum Keramik

\begin{tabular}{|c|c|c|c|c|c|c|}
\hline $\begin{array}{c}\text { Investasi } \\
\text { Aktiva } \\
\text { Tetap } \\
\text { (Rp) }\end{array}$ & $\begin{array}{c}\text { Biaya } \\
\text { Tetap } \\
(\mathbf{R p})\end{array}$ & $\begin{array}{c}\text { Marjin } \\
\text { Kontribusi } \\
\text { dlm Proporsi } \\
\text { (Rp/Unit) }\end{array}$ & $\begin{array}{l}\text { Break } \\
\text { Even } \\
\text { Point } \\
\text { (Unit) }\end{array}$ & $\begin{array}{c}\text { Break } \\
\text { Even } \\
\text { Point } \\
(\mathbf{R p})\end{array}$ & $\begin{array}{c}\text { Kriteria } \\
\text { Keputusan }\end{array}$ & $\begin{array}{c}\text { Keputusan } \\
\text { Investasi }\end{array}$ \\
\hline $500.000 .000,00$ & $53.319 .900,00$ & $21.696,29$ & $2.457,56$ & $256.911 .104,11$ & BEP < Unit penjualan & Layak \\
\hline
\end{tabular}




\section{Jurnal Keuangan dan Perbankan | KEUANGAN}

Vol. 21, No.1, Januari 2017: 47- 59

kemampuan menghasilkan laba (profitability) suatu investasi, tetapi mengukur jangka waktu pengembalian investasi. Analisis investasi jasa pengujian produk tableware khususnya keramik berglasir untuk alat makan dan minum keramik pada BTIKK layak untuk dilanjutkan karena jangka waktu pengembalian investasi hanya 4,65 tahun, sedangkan investasi diperkirakan 10 (sepuluh) tahun dalam arti sisa waktu selama 5,36 tahun masih mungkin memberikan hasil atau aliran kas masuk bagi BTIKK.

Analisis net present value memberikan hasil sebesar Rp206.043.764,69. Angka ini diperoleh dengan mengurangi PV proceeds dengan PV investasi. PV proceeds mencerminkan jumlah nilai sekarang dari taksiran laba bersih setelah pajak ditambah biaya penyusutan tahunan selama 10 tahun yang didiskontokan dengan discount factor $10,00 \%$, yang hasilnya adalah Rp706.043.764,69. PV investasi adalah nilai sekarang dari investasi yang dilakukan yang identik dengan initial investment, yang besarnya pada awal tahun pertama adalah Rp500.000. 000,00. Apabila nilai investasi didiskontokan dengan discount factor $10,00 \%$ pada awal tahun pertama atau tahun ke-0, maka akan diperoleh angka sebesar Rp500.000.000,00. Nilai NPV sebesar Rp206.043.764,69 merupakan angka yang posisitp. Menurut kriteria kelayakan investasi, NPV positif mencerminkan suatu investasi layak untuk dilanjutkan. Dengan demikian, berdasarkan kriteria kelayakan, investasi jasa pengujian produk tableware khususnya keramik berglasir untuk alat makan dan minum keramik pada BTIKK adalah layak diteruskan.

Hasil analisis profitability index pada BTIKK menghasilkan angka sebesar 1,41. Angka ini diperoleh dengan membandingkan PV proceeds dengan $P V$ investasi. $P V$ proceeds mencerminkan jumlah nilai sekarang dari taksiran laba bersih setelah pajak ditambah biaya penyusutan tahunan selama 10 tahun yang didiskontokan dengan discount factor $10,00 \%$, yang hasilnya adalah Rp706.043.764,69.
Angka ini merupakan pembilang yang akan dibagi dalam menghitung PI. PV investasi adalah nilai sekarang dari investasi yang dilakukan yang identik dengan initial investment, yang besarnya pada awal tahun pertama adalah Rp500.000.000,00. Angka ini merupakan penyebut yang akan membagi dalam menghitung PI. Apabila nilai investasi didiskontokan dengan discount factor $10,00 \%$ pada awal tahun pertama atau tahun ke-0, maka akan diperoleh angka sebesar Rp500.000.000,00. Kriteria kelayakan investasi untuk analisis profitability index nilai PI yang lebih besar dari 1. Investasi jasa pengujian produk tableware khususnya keramik berglasir untuk alat makan dan minum keramik pada BTIKK layak diteruskan, karena memberikan PI sebesar 1,41 yang nilainya lebih besar dari 1 .

Hasil analisis internal rate of return pada BTIKK adalah $18,93 \%$. Internal rate of return mencerminkan tingkat pengembalian internal yang diharapkan dicapai oleh BTIKK atas investasi yang dilakukan selama 10 tahun dengan mengasumsikan hal-hal lainnya bersifat konstan. Angka internal rate of return sebesar 18,93\% merupakan angka yang cukup tinggi jika dibandingkan dengan tingkat bunga yang sedang berlaku saat ini $(10,00 \%)$ atau yang dipakai dalam menghitung PV proceeds dan PV investasi. Hal ini berarti bahwa BTIKK mampu mencapai tingkat profitabilitas sebesar 18,93\% dari investasi jasa pengujian produk tableware khususnya keramik berglasir untuk alat makan dan minum keramik yang dilakukan selama 10 tahun kedepan. Dengan membandingkan tingkat bunga yang berlaku saat ini (asumsi 10,00\%), dan internal rate of return yang dapat dicapai BTIKK $(18,93 \%)$, maka investasi yang dimaksud dapat diteruskan karena dapat memberikan kelebihan tingkat keuntungan sebesar 9,93\%. Kelebihan tingkat keuntungan (pengembalian) sebesar 9,93\% menunjukkan bahwa apabila BTIKK melakukan investasi jasa pengujian produk tableware khususnya keramik berglasir untuk alat makan dan minum keramik, maka BTIKK akan memperoleh manfaat finansial lebih 
sebesar 9,93\% dibandingkan apabila dana yang dimiliki disimpan di bank. Tingkat keuntungan (pengembalian) merupakan salah satu variabel yang harus diperhatikan oleh suatu perusahaan (organisasi) dalam meningkatkan kinerja keuangannya baik dalam jangka pendek maupun jangka panjang.

Hasil analisis break even point memberikan angka sebesar 2.457,56 unit atau Rp256.911.104,11 per tahun. Break even point mencerminkan pada tingkat (unit atau rupiah) berapa investasi jasa pengujian produk tableware khususnya keramik berglasir untuk alat makan dan minum keramik yang dilakukan oleh BTIKK akan mencapai keadaan impas atau tidak menderita rugi dan tidak memperoleh keuntungan. Pada penjualan sebesar 2.457,56 unit sampel atau Rp256.911.104,11 per tahun BTIKK mendapatkan hasil penjualan jasa pengujian sama dengan total biaya yang dikeluarkan baik biaya variabel maupun biaya tetap atau dalam kondisi titik impas (pulang pokok). Mengacu pada penjualan jasa pengujian yang dilakukan oleh BTIKK, maka dihasilkan estimasi rata-rata penjualan dalam setahun adalah 25 sampel $\times 12 \times 3 \times 7=6.300$ sampel (unit) atau Rp783.000.000,00. Kondisi penjualan BEP $(2.567,56$ unit sampel atau Rp256.911.104,11) lebih rendah dari estimasi penjualan rata-rata tahunan (6.300 unit sampel atau Rp783.000.000,00), hal ini berarti investasi jasa pengujian produk tableware khususnya keramik berglasir untuk alat makan dan minum keramik memenuhi syarat untuk dilanjutkan pada periode mendatang. Pada estimasi penjualan sebesar 6.300 unit sampel, BTIKK masih dapat menikmati keuntungan 3.732,44 unit sampel diatas penjualan pulang pokok $(2.567,56$ unit sampel).

Komparasi hasil penelitian analisis keuangan investasi pada BTIKK dan investasi pada usaha lain yang dilakukan oleh beberapa peneliti. Abdullah (2015) dalam penelitiannya menghasilkan NPV Rp1.063.315.999,00> 1, IRR 17,00\% > 16,00\%, PP 1 tahun 1 bulan $<5$ tahun, dan PI $4,00>1$, yang sim- pulannya bahwa investasi layak diteruskan. Suindrawan \& Sudiarta (2013) dalam penelitiannya menghasilkan PP 1 tahun 7 bulan 28 hari $<8$ tahun, NPV Rp 446.314.013,00> 0, PI 2,30> 1, dan IRR $61,60 \%>18,00 \%$, simpulannya bahwa investasi pembelian mesin yang dilakukan layak untuk dilanjutkan.

Hasil penelitian analisis keuangan investasi jasa pengujian produk tableware khususnya keramik berglasir untuk alat makan dan minum keramik pada BTIKK dapat memberikan kontribusi terhadap perkembangan ilmu manajemen keuangan di masa yang akan datang, karena penelitian ini berfokus pada investasi jasa pengujian produk keramik yang masih sangat terbatas dibandingkan jasa pengujian lainnya sementara tuntutan terhadap produk ber SNI semakin tinggi, sehingga secara tidak langsung akan menjadi dasar atau acuan bagi jenis pengujian lainnya dalam memutuskan suatu investasi. Produk keramik masa depan dituntut berkualitas dan aman bagi pengguna. Jaminan kualitas hanya dapat dikeluarkan oleh lembaga yang berkompeten melalui proses pengujian. Pengujian membutuhkan investasi peralatan uji. Keputusan investasi ditentukan oleh layak tidaknya analisis finansial yang merupakan bagian dari ilmu manajemen keuangan.

\section{SIMPULAN DAN SARAN}

\section{Simpulan}

Penelitian ini bertujuan untuk mengetahui tingkat kelayakan perluasan investasi jasa pengujian produk kreatif keramik pada BTIKK-BPPT ditinjau dari sisi kriteria penilaian investasi manajemen keuangan, yaitu payback period, net present value, profitability index (PI), internal rate of return, dan break even point serta untuk memberikan dasar pengambilan keputusan melanjutkan atau meghentikan investasi bagi BTIKK-BPPT.

Berdasarkan hasil dan pembahasan dapat disimpulkan bahwa investasi jasa pengujian produk 
tableware, khususnya keramik berglasir untuk alat makan dan minum keramik pada BTIKK yang disyaratkan oleh BSN sesuai dengan SNI 7275:2008 adalah layak untuk dilanjutkan atau dilaksanakan, karena memenuhi kriteria penilaian kelayakan investasi dengan menghasilkan payback period sebesar 4,65 tahun yang nilainya lebih kecil dari jangka waktu investasi yaitu 10,00 tahun. Hal ini berarti sisa waktu sebesar 5,35 tahun masih memungkinkan bagi BTIKK untuk memperoleh pendapatan atau aliran kas operasional.

Net present value sebesar Rp206.043.764,69 yang nilainya positif. Hal ini berarti ada kelebihan jumlah nilai sekarang dari aliran kas masuk (proceeds) yang besarnya Rp706.043.764,69 dengan investasi awal (initial investment) yang nilainya Rp500.000.000,00, profitability index sebesar 1,41 yang nilainya lebih besar dari 1,00. Hal ini berarti apabila dibandingkan antara nilai sekarang dari aliran kas masuk (proceeds) dengan investasi awal (initial investment), maka nilai aliran kas masuk (proceeds) lebih besar daripada nilai investasi awal (initial investment) atau dengan kata lain hasil perbandingannya melebihi 1 .

Internal rate of return menghasilkan angka $18,93 \%$ yang nilainya lebih besar dari 10,00\%. Hal ini berarti tingkat pengembalian internal yang diharapkan dari investasi jasa pengujian yang dilakukan oleh BTIKK $(18,93 \%)$ melebihi tingkat bunga yang sedang berlaku atau yang dipakai sebagai perhitungan discount factor $(10,00 \%)$. Internal rate of return yang lebih ini mengindikasikan investasi yang dilakukan memberikan tingkat keuntungan yang lebih besar daripada keuntungan saat ini.

Break even point menghasilkan angka sebesar 2.567,56 unit sampel atau Rp256.911.104,11 yang lebih kecil atau kurang dari 6.300,00 unit sampel atau Rp783.000.000,00. Hal ini berarti bahwa inves tasi jasa pengujian yang dilakukan oleh BTIKK mencapai titik pulang pokok atau impas pada penjualan 2.567,56 unit sampel atau Rp 256.911. 104,11. Pada kondisi tersebut, BTIKK tidak men- derita kerugian dan tidak memperoleh keuntungan atau dengan kata lain seluruh penjualan yang diperoleh dipakai untuk menutup biaya variabel dan biaya tetap. Pada hal estimasi rata-rata penjualan tahunan mencapai angka 6.300,00 unit sampel atau Rp783.000.000,00, jauh melebihi nilai BEP.

\section{Saran}

Pada penelitian ini dapat disarankan kepada BTIKK, agar segera melaksanakan rencana investasi perluasan kegiatan jasa pengujian produk tableware khususnya keramik berglasir untuk alat makan dan minum, karena dari sisi keuangan $(P P, N P V$, $P I, I R R$, dan BEP) analisis investasi yang direncanakan memenuhi kriteria kelayakan secara komulatif.

Pengusaha (IKM) Keramik, agar dalam melakukan rencana investasi dapat menggunakan hasil penelitian ini sebagai dasar pengembangan ilmu pengetahuan perinvestasian dalam dunia bisnis.

Penelitian selanjutnya agar menggunakan analisis keuangan sebagai kriteria utama dalam memutuskan kriteria kelayakan investasi terutama pada jenis usaha yang spesifik yang baru berkembang dalam dunia bisnis.

\section{DAFTAR PUSTAKA}

Abdullah, F. 2015. Analisis Kelayakan Investasi Aktiva Tetap Pembelian Mesin Printing Pada PT Radja Digital Printing Samarinda. Jurnal Ilmu Administrasi Bisnis, 3(2): 297-310.

Astiti, N.K.A. 2014.Uang Kepeng Sepanjang Masa: Perspektif Arkeologi dan Ekonomi Kreatif di Propinsi Bali. Forum Arkeologi, 27(1): 45-56.

Badan Standarisasi Nasional (BSN). 2008. Standar Nasional Indonesia (SNI) 7275:2008 (Keramik Berglasir - Tableware - Alat Makan dan Minum. Jakarta. BSN.

Baridwan, Z. 2000. Intermediate Accounting. Yogyakarta: Badan Penerbit Fakultas Ekonomi- Universitas Gadjah Mada. 
Haming \& Murdifin. 2010. Studi Kelayakan Investasi Proyek dan Bisnis. Jakarta: Bumi Aksara.

Balai Besar Industri Keramik Bandung. 2015. Tarif Pengujian Keramik. http:/www.bbk.go.id/ index.php/main/bahasa/indonesia? Redirect $=$ page $/$ index $/ 46$. Diakses tanggal 14 Oktober 2016.

Ikatan Akuntansi Indonesia. 2004. Standar Akuntansi Indonesia. Jakarta: Salemba.Empat.

Mulyadi. 2013. Akuntansi Manajemen (Konsep, Manfaat, dan Reayasa). Edisi 2. Yogyakarta. Bagian Penerbitan Sekolah Tinggi Ilmu Ekonomi YKPN.

Normal, I.N. 2013. Pengaruh Komposisi $\mathrm{Fe}_{2} \mathrm{O}_{3}$ dan $\mathrm{P}_{4} \mathrm{O}$ terhadap Karakteristik Fisik dan Variabel Keuangan yang Menjadi Dasar Pengambilan Keputusan Bisnis Glasir RUS pada UPT PSTKP Bali-BPPT. Jurnal Wacana Ekonomi, 11(1): 56-72.

Riyanto, B. 2011. Dasar-dasar Pembelanjaan Perusahaan. Yogyakarta: Badan Penerbit Fakultas EkonomiUniversitas Gadjah Mada.

Rolita, R. 2014. Hubungan Struktur Modal dan Keputusan Investasi pada Perusahaan Manufaktur. Jurnal Keuangan dan Perbankan, 18(3): 370-383.
Rudianto. 2013. Akuntansi Manajemen (Informasi Untuk Pengambilan Keputusan Strategis). Jakarta: Erlangga.

Rudianto. 2008. Pengantar Akuntansi. Jakarta: Erlangga

Sudana, I.W. 2014. Strategi Pengembangan Kerajinan Keramik Gerabah Tradisional Gorontalo Guna Mendukung Industri Kreatif. Mudra (Jurnal Seni Budaya), 29(2): 163-180.

Suindrawan, A.A.N.G. \& Sanjaya, I.N.W. 2012. Analisis Kinerja Pusat-pusat Pertanggungjawaban Pada PT Bali Reka Mahesa Cargo di Denpasar. Jurnal Ilmiah Forum Manajemen (JIFM), 10(1): 96-114.

Suindrawan, A.A.N.G. \& Sudiarta, D.G.A.J. 2013. Analisis Reevaluasi Investasi Aktiva Tetap Ditinjau dari Aspek Finansial (Studi Kasus pada UD Utama Denpasar). Jurnal Ilmiah Forum Manajemen (JIFM), 11(1): 109-121.

Sukasih, N.K. 2015. Pengambilan Keputusan dalam Investasi Saham dengan Pendekatan Fundamental terhadap Laporan Keuangan di Pasar Modal Indonesia. Jurnal Bisnis dan Kewirausahaan (JBK), 11(2): 184.

Wiagustini, N.L.P. 2014. Manajemen Keuangan. Cetakan Pertama. Denpasar: Udayana University Press. 